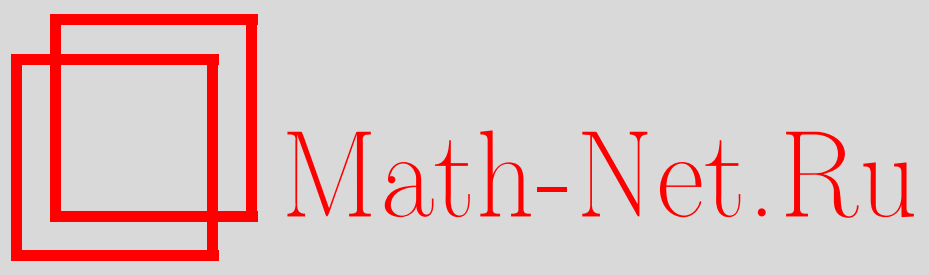

М. Бойти, Ф. Пемпинелли, Б. Принари, А. К. Погребков, Нелинейная физика: теория и эксперимент. IV, TMФ, 2007, том 151, номер 3, 341-344

DOI: https://doi.org/10.4213/tmf6048

Использование Общероссийского математического портала Math-Net.Ru подразумевает, что вы прочитали и согласны с пользовательским соглашением http://www . mathnet.ru/rus/agreement

Параметры загрузки:

IP: 54.205 .225 .156

26 апреля 2023 г., 12:33:17

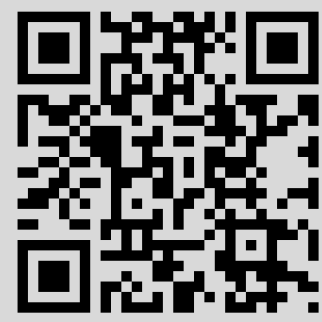




\section{НЕЛИНЕЙНАЯ ФИЗИКА: ТЕОРИЯ И ЭКСПЕРИМЕНТ. IV}

Четвертая конференция "Нелинейная физика: теория и эксперимент" проходила в Байя Верде вблизи г. Галлиполи в южной Италии с 22 июня по 1 июля 2006 г. Эта конференция представляет собой этап более чем двадцатипятилетнего активного участия университета г. Лечче в международном научном сотрудничестве в области нелинейной физики. Первая конференция "Нелинейные эволюционные уравнения и динамические системы” (NEEDS) была организована в г. Лечче в 1979 г. Впоследствии, в 1985, 1991 и 1993 гг., в Галлиполи были проведены еще три конференции NEEDS. Также в Галлиполи были проведены три конференции "Нелинейная физика: теория и эксперимент" в 1995, 2002 и 2004 гг. и конференция "Нелинейность, интегрируемость и все такое: двадцать лет спустя NEEDS'79" в 1999 г. Основная цель этих встреч заключалась в том, чтобы собрать вместе квалифицированных ученых и молодых исследователей, изучающих нелинейные проблемы, и предоставить им возможность обсудить последние разработки и достижения, а также будущие перспективы.

Как отражено в названии конференции, акцент делается и на теорию, и на эксперимент. Истинно междисциплинарное совещание дает научному сообществу, занимающемуся нелинейными проблемами, уникальную возможность научного взаимодействия между математиками, теоретиками и экспериментаторами. Интерес представляют приложения к нелинейной оптике, молекулярной динамике, динамике жидкостей, плазменным волнам, гидродинамике, квантовой электронике, физике твердого тела, теории струн, гравитации и т.д. Рассматриваются также математические подходы, в том числе задачи, касающиеся непрерывных и дискретных нелинейных систем, как на классическом, так и на квантовом уровне. Конкретные теоретические направления включают обратную задачу рассеяния, гамильтоновы структуры, геометрические подходы, свойство Пенлеве, симметрии и другие близкие проблемы.

Что касается прикладных проблем, особое внимание было уделено организации сессий, посвященных задачам высокобитных оптических коммуникаций и динамике импульсов в оптических средах.

Были приложены значительные усилия для обеспечения широкого присутствия ученых из тех стран, где финансирование фундаментальных исследований ограничено. На конференции присутствовало 98 участников из 20 стран: Италии, России, США, Польши, Франции, Израиля, Великобритании, Австралии, Швеции, Болгарии, Канады, Испании, Тайваня, Турции, Бельгии, Португалии, Сингапура, Германии, Индии и Грузии. Следует отметить, что почти все участники сделали доклады (84 получасовые лекции) или представили стендовые доклады. Кроме заявленной программы, конференция замечательна многочисленными неформальными обменами идеями и свободными обсуждениями.

Этот и два следующих выпуска журнала "Теоретическая и математическая физика" содержат большинство докладов, сделанных на конференции и прошедших стандартную процедуру рецензирования и редактирования. Мы считаем, что широкое разнообразие затронутых тем и качество представленных материалов позволяют считать публикуемые труды конференции адекватным отражением современного 
состояния дел на переднем крае исследований в рассматриваемых областях. Разумеется, эти работы не дают исчерпывающего описания всего предмета, но дают представление о самых новых результатах и, тем самым, стимулируют заинтересованного читателя.

Конференция была организована Марко Бойти, Флорой Пемпинелли и Барбарой Принари, а также соорганизаторами Марком Абловицем и Андреем Погребковым. Спонсорами конференции выступили Университет г. Лечче, M.I.U.R. (PRIN 2004 "Sintesi"), I.N.F.N. (Italy) и Consortium E.I.N.S.T.E.I.N. Организаторы благодарят Российский фонд фундаментальных исследований за существенную поддержку российских участников.

Организаторы выражают благодарность Отделению физики Университета г. Лечче за предоставленные услуги. Отдельно они благодарят М. К. Джерарди, которая принимала активное участие в организации конференции. Редакторы этих трудов хотели бы выразить благодарность всем авторам, предоставившим свои статьи.

Наконец, организаторы выражают особую признательность Редколлегии журнала "Теоретическая и математическая физика" за возможность опубликовать труды конференции.

Лечче, март 2007 г.

М. Бойти, Ф. Пемпинелли, Б. Принари, А. К. Погребков

В этом и двух следующих выпусках мы публикуем труды конференции "Нелинейная физика: теория и эксперимент. IV".

В т. 152, № 1 будут опубликованы следующие доклады:

$\Phi$. Калоджеро. Изохронные системы и их квантование

Х. Ф. Кариньена, Х. Клементе-Гайардо, Дж. Мармо. Геометризация квантовой механики

Р. Кэрролл. Флуктуации метрики, энтропия и уравнение Уилера-Де Витта

Юй-Тун Чэнь, Цзень-Ху Чан, Мин-Хсиень Ту. Дополнительные симметрии и преобразования Беклунда для бездисперсионной иерархии Дима

С. де Лилло, Г. Лупо, М. Соммакал. Решения нелинейной задачи теплопроводности на полупрямой

А. Димакис, Ф. Мюллер-Хойсен. Иерархии Бюргерса и Кадомцева-Петвиашвили: метод функционального представления

А. М. Грюндланд, Б. Юард. О решениях ранга $k$ систем гидродинамического типа

А. В. Киселев. Алгебраические свойства деформаций по Гарднеру интегрируемых систем

С. Б. Лебле. Метод одевания в квантовых моделях вещество+излучение

Дж.-Х. Ли, О. К. Пашаев. Солитонные решения резонансного нелинейного уравнения Шредингера с нетривиальными граничными условиями и билинейный метод Хироты

С. В. Манаков, П. М. Сантини. Иерархия интегрируемых уравнений в частных производных в размерности $2+1$, ассоциированная с пучком одномерных векторных полей 
Р. Р. Парвани. Некоторые мысли по поводу теоретико-информационного обоснования нелинейного уравнения Шредингера

О. К. Пашаев, 3. Н. Гюркан. Абелевы вихри Черна-Саймонса и голоморфная иерархия Бюргерса

K. Роджерс, В. К. Шиф, К. В. Чоу. Новый класс модельных материальных уравнений в нелинейной теории упругости. Построение на основе теории Левнера

Дж. М. Спайт. Преломление магнитных пузырей и квазибризеры в неоднородных антиферромагнетиках

В т. 152, № 2 будут опубликованы следующие доклады:

М. Беккариа, К. Ортикс. АдС/КТП-дуальность в режиме сильной связи

С. де Никола, Р. Феделе, М.А. Манько, В.И. Манько. Новые неравенства для томограмм в вероятностном представлении квантовой механики

К. Гарола, С. Соццо. О физической интерпретации частичных следов: две нестандартные точки зрения

Дж. Харнад, А. Ю. Орлов. Фермионный подход к построению статистической суммы многоматричных моделей и многокомпонентной иерархии цепочки Тоды

А. Ю. Хренников. Квантовая механика как квадратичная тейлоровская аппроксимация классической механики: конечномерный случай

Ф. Канфора, Л. Паризи, Г. Вилази. Нелинейные гравитационные волны, их поляризация и реалистичные источники

Р. Хомерики, Дж. Леон, С. Руффо, С. Вимбергер. Нелинейная динамика в потенциалах вида двойной прямоугольной ямы

К. Клейн, В. Б. Матвеев, А. О. Смирнов. Цилиндрическое уравнение КадомцеваПетвиашвили: старые и новые результаты

Т. А. Ч. Майоло, Ф. Делла Сала, Л. Мартина, Дж. Солиани. Зацепление электронов во взаимодействующих молекулах

C. К. Манкас, С. Р. Чудхури. Новый вариационный подход к пульсирующим солитонам в уравнении Гинзбурга-Ландау для потенциала в виде кубики-квинтики

Е. М. Маслов, Л.А. Калякин, А.Г. Шагалов. Резонансный захват фазы бризера внешним возмущением

О.И. Мохов. Теория подмногообразий, уравнения ассоциативности двумерных топологических квантовых теорий поля и фробениусовы многообразия

М. Палезе, Е. Уинтеррот. О соотношении между морфизмом Якоби и гессианом в калибровочно-естественных теориях поля

Дж. Руджери. Квантовые каналы с памятью, распределенной по закону Гаусса

О. А. Шустова. Квантовое моделирование нелинейной динамики цен на акции: бомовский подход 